\title{
Influence of Induced Polyploidy on Fertility and Morphology of Rudbeckia Species and Hybrids
}

\author{
Kelly M. Oates ${ }^{1}$, Thomas G. Ranney ${ }^{2,4}$, and Darren H. Touchell ${ }^{3}$ \\ Mountain Crop Improvement Lab, Department of Horticulture Science, \\ Mountain Horticultural Crops Research and Extension Center, North \\ Carolina State University, Mills River, NC 28759-3423
}

Additional index words. Asteraceae, autotetraploid, allotetraploid, blackeyed Susan, chromosome doubling, coneflower, whole genome duplication, plant breeding

\begin{abstract}
Rudbeckia spp. are adaptable and valuable ornamental wildflowers. Development of new varieties of Rudbeckia spp., with improved commercial characteristics, would be highly desirable. Interspecific hybridization and induced polyploidy may be avenues for improvement within the genus. The objective of this study was to evaluate fertility, morphology, phenology of flowering, and perennialness (overwintering survival) for lines of diploid and induced allotetraploids of $R$. subtomentosa $\times$ hirta and diploid and autotetraploids of $R$. subtomentosa 'Henry Eilers'. Polyploid lines were developed and propagated in vitro and then grown ex vitro in a randomized complete block design with 12 replications. Compared with their diploid counterparts, autotetraploid lines of $\boldsymbol{R}$. subtomentosa 'Henry Eilers' had similar internode lengths, plant heights, number of stems, flowering times (date at first anthesis), and fall and spring survival $(100 \%)$; reduced number of inflorescences and male and female fertility; and increased inflorescence diameters. Compared with their diploid counterparts, allotetraploids of $\boldsymbol{R}$. subtomentosa $\times$ hirta had similar internode lengths, reduced number of inflorescences, delayed flowering times, and increased pollen staining. Allotetraploids had limited male and female fertility compared with no detectable fertility in their diploid counterparts. Plant height and number of stems either decreased or showed no change with induced allotetraploidy. Spring survival of diploid hybrid genotypes ranged from $0 \%$ to $82 \%$ and was not improved in the allotetraploid hybrids. For a given genotype, some polyploidy lines varied significantly in certain morphological traits (e.g., plant height) indicating somaclonal variation may have developed in vitro or there were variable genomic or epigenetic changes associated with induced polyploidy.
\end{abstract}

The genus Rudbeckia consists of $\approx 30$ species endemic to North America (Armitage, 1997; Palmer et al., 2009). The genus includes annuals, biennials, and perennial species (Perdue, 1957) and is divided into two subgenera, Rudbeckia subg. Macrocline and Rudbeckia subg. Rudbeckia (Urbatsch et al., 2000). These two subgenera can be distinguished cytogenetically with $R$. subg. Macrocline having

Received for publication 27 Apr. 2012. Accepted for publication 28 June 2012.

This research was funded in part by the North Carolina Agricultural Research Service (NCARS), Raleigh, NC.

Technical assistance of Joel Mowrey, Nathan Lynch, Tom Eaker, and Jeremy Smith is gratefully appreciated.

Use of trade names in this publication does not imply endorsement by the NCARS of products named nor criticism of similar ones not mentioned. This research is from a MS thesis by the senior author.

${ }^{1}$ Graduate Research Assistant.

${ }^{2}$ Professor.

${ }^{3}$ Research Associate.

${ }^{4}$ To whom reprint requests should be addressed; e-mail tom_ranney@ncsu.edu. a base chromosome number of 18 and $R$. subg. Rudbeckia having a base chromosome number of 19 (Urbatsch et al., 2000). Many of the commercially important species of Rudbeckia are from $R$. subg. Rudbeckia. Two of these species, $R$. subtomentosa and $R$. hirta, are closely allied based on phylogeny and are commonly cultivated wildflowers (Urbatsch et al., 2000).

Rudbeckia subtomentosa is a durable, diploid $(2 n=2 \mathrm{x}=38)$ perennial, hardy to USDA zone 4 . It is well adapted to many environments and has showy yellow ray florets. The tall stature of $R$. subtomentosa ( 2 to $3 \mathrm{~m}$ ) limits its use within many cultivated landscapes. A reduction in height and an increase in the range of flower colors in $R$. subtomentosa would be highly desirable. Rudbeckia subtomentosa 'Henry Eilers' is a cultivar with showy tubular ray florets providing additional ornamental interest.

The annual species, Rudbeckia hirta, includes diploid $(2 n=2 \mathrm{x}=38)$ and tetraploid $(2 n=4 \mathrm{x}=76)$ cultivars with a diverse range of flower colors and forms (Palmer et al., 2009). Cultivars of $R$. hirta range in mature height from 0.5 to $1.0 \mathrm{~m}$ with tetraploid cultivars typically having larger flowers and greater height (Hansen and Stahl, 1993; Palmer et al., 2009). However, R. hirta is short-lived and susceptible to certain diseases including cercospora leaf spot (Cercospora sp.) and rhizoctonia blight (Rhizoctonia sp.) (Fulcher et al., 2003; Harkess and Lyons, 1994).

Interspecific hybrids between $R$. subtomentosa and $R$. hirta were developed at the Mountain Crop Improvement Laboratory (Palmer et al., 2008) to potentially combine desirable traits from both species including moderate plant height, a range of flower colors and forms, disease resistance, and perennialness. However, like many wide hybrids, these appeared to be infertile. Hybrid sterility may occur when chromosomes of different taxa are sufficiently different that pairing of chromosomes during meiosis fails (asynapsis) (Martin and Jouve, 1992). The different chromosome sizes of $R$. subtomentosa and R. hirta may be creating a barrier to fertility in hybrids. Palmer et al. (2009) found the 1Cx DNA content (DNA content of one complete set of chromosomes) to vary among Rudbeckia species by $320 \%$. Rudbeckia subtomentosa had a 1Cx DNA content of $11.0 \pm 0.1 \mathrm{pg}$, whereas that of $R$. hirta ranged from $3.4 \pm 0.2 \mathrm{pg}$ to $4.0 \pm$ $0.2 \mathrm{pg}$.

In many cases, fertility can be restored in wide hybrids by doubling the genomes to create allopolyploids. Allopolyploids have duplicate homologous chromosome sets from each original parent that allows for disomic pairing and the formation of balanced gametes (Contreras et al., 2007; Lu and Bridgen, 1997; Olsen et al., 2006; Ranney, 2006). In addition to restored fertility, allopolyploids may display improved ornamental characteristics that are often intermediate between the two parents (Horn, 2002). Similarly, autopolyploids may also display improved characteristics such as an increase in flower size and vegetative tissues along with a decrease in internode lengths, although morphological responses vary (Horn, 2002). Furthermore, autotetraploids may also have a slower growth rate compared with their diploid cytotypes (Chahal and Gosal, 2002)

A greater understanding of the influence of induced polyploidy on fertility and morphology of Rudbeckia will better enable the development of improved varieties. The objectives of this study were to evaluate fertility, morphology, phenology of flowering, and perennialness for lines of diploid and induced allotetraploids of $R$. subtomentosa $\times$ hirta and diploid and induced autotetraploids lines of R. subtomentosa 'Henry Eilers'.

\section{Materials and Methods}

In vitro polyploid induction. Allotetraploids of diploid interspecific hybrids of $R$. subtomentosa $\times$ hirta 'Toto Gold' and autotetraploids of $R$. subtomentosa 'Henry Eilers' were previously developed at the Mountain Crop Improvement Laboratory (Palmer et al., 2008). Briefly, shoot apices were treated in vitro with $30 \mu \mathrm{M}$ oryzalin for $5 \mathrm{~d}$ resulting in multiple tetraploid lines of each genotype (Fig. 1). All polyploid 


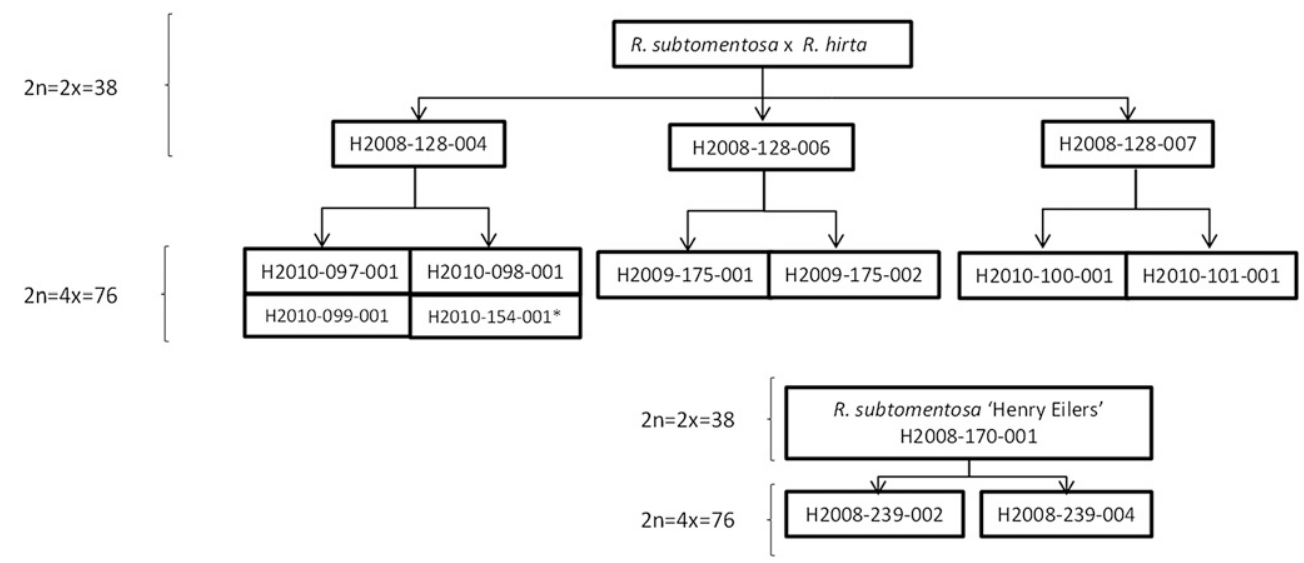

Fig. 1. Origin and parentage of allotetraploid and autotetraploid Rudbeckia lines. *H2010-154-001 was used for male fertility studies in 2011.

lines and their diploid cytotypes were maintained in tissue culture by subculturing monthly to bimonthly on Driver and Kuniyuki Walnut basal salts and vitamins (Driver and Kuniyuki, 1984) supplemented with myoinositol at $0.1 \mathrm{~g} \cdot \mathrm{L}^{-1}$, MES monohydrate at $0.1 \mathrm{~g} \cdot \mathrm{L}^{-1}, 2 \mu \mathrm{M}$ BAP, $30 \mathrm{~g} \cdot \mathrm{L}^{-1}$ sucrose, solidified with $7.5 \mathrm{~g} \cdot \mathrm{L}^{-1}$ agar, $\mathrm{pH}$ adjusted to $5.75 \pm 0.03$, and maintained under standard culture conditions $\left[23 \pm 2{ }^{\circ} \mathrm{C}\right.$ and a 16-h photoperiod of $30 \mu \mathrm{mol} \cdot \mathrm{m}^{-2} \cdot \mathrm{s}^{-1}(400$ to $700 \mathrm{~nm}$ ) provided by cool-white fluorescent lamps]. On Mar. 2010, microcuttings were placed onto a rooting media consisting of Murashige and Skoog basal salts and vitamins supplemented with myoinositol at $0.1 \mathrm{~g} \cdot \mathrm{L}^{-1}$, MES monohydrate at $0.1 \mathrm{~g} \cdot \mathrm{L}^{-1}$, $5 \mu \mathrm{M}$ IBA, $30 \mathrm{~g} \cdot \mathrm{L}^{-1}$ sucrose, solidified with $7.5 \mathrm{~g} \cdot \mathrm{L}^{-1}$ agar, $\mathrm{pH}$ adjusted to $5.75 \pm 0.03$, and maintained under standard culture for 1 week to promote root initiation before being transferred into 72-cell trays (vol. $40 \mathrm{~mL}$ per cell) containing a seedling mix of 1 peat: 1 vermiculite (by vol.) and $1.19 \mathrm{~kg} \cdot \mathrm{m}^{-3}$ micronutrients (Micromax ${ }^{\circledR}$; Scotts Company LLC, Marysville, $\mathrm{OH})$.

Flow cytometry. Ploidy levels of all plants were confirmed using flow cytometry (Partec PA-I Ploidy Analyzer or Partec PA II; Partec) following procedures in Palmer et al. (2009). Pisum sativum 'Ctirad', with a known DNA content of $2 \mathrm{C}=8.75 \mathrm{pg}$, was used as an internal standard (Greihuber et al., 2007) to determine relative genome size. Ploidy level was determined by comparing the relative genome size of samples tested with published values for the diploid parents of the interspecific hybrids and $R$. 'Henry Eilers' (Palmer et al., 2009).

Evaluation of morphological traits and perennialness. Plants were transferred from 72 -cell trays to 0.80 - $\mathrm{L}$ pots in a $100 \%$ pine bark media [supplemented with $1.04 \mathrm{~kg}$ lime and $0.74 \mathrm{~kg}$ granular micronutrients (Micromax ${ }^{\circledR}$; The Scotts Co.), per cubic meter] on 27 Apr. 2010. Plants were randomized on a greenhouse bench and allowed to grow for 3 weeks and then moved outdoors under 50\% shade for 1 week. On 27 May 2010, plants were transplanted to 5.7-L pots in a pinebark media and placed on a gravel container pad, in full sun, in a randomized complete block design with 12 blocks with one plant (replication) from each of the 13 taxa (see Fig. 1) per block. Each container was topdressed with $\approx 24 \mathrm{~g}$ of 5- to 6-month slow-release fertilizer (Osmocote ${ }^{\circledR}$ plus, 15-9-12; The Scotts Co.). Additional plants of diploid $R$. hirta 'Toto Gold' and tetraploid $R$. hirta 'Cherry Brandy' were randomly interspersed as fertile pollen donors. Other diploid seedlings of wild-type $R$. subtomentosa were within $30 \mathrm{~m}$ on the same container pad but not formally included in this experiment. The date of first anthesis was recorded for each plant in the experiment. Inflorescence diameter was measured at anthesis for three randomly selected inflorescences (subsamples) per plant. Internode length was determined on one randomly selected stem per plant and included three measurements: the second internode below the flower, the second internode from the base of the plant, and the fifth internode from the base of the plant. Plant height, number of flowers, and number of basal stems for all plants in the experiment were measured on 12 Aug. 2010. Other traits such as petal and flower head morphology were also observed and recorded.

To evaluate perennialness, survival was recorded in Sept. 2010 and May 2011. Plants were overwintered in containers in a heated (minimum temperature of $3{ }^{\circ} \mathrm{C}$ ), polyethylenecovered greenhouse in a randomized complete design.

Evaluation of fertility. To evaluate male fertility, pollen was collected from newly opened florets from each plant between 1030 HR and 1130 HR. Pollen was placed on a glass slide and stained with $40 \mu \mathrm{L}$ of aceticcarmine $(1 \%)$, covered with a coverslip, and incubated at room temperature for a minimum of $90 \mathrm{~min}$. Well-formed grains stained pink/ red were scored as viable. Each sample consisted of a minimum of 200 grains. As a result of variation in pollen availability, data were collected during both 2010 and 2011.

To evaluate female fertility, three randomly selected seed heads from each plant in the experimental block were collected on 28 Aug. 2010. Seed heads were air-dried, cleaned, and stored at $4{ }^{\circ} \mathrm{C}$. Seeds were sown on 12 Dec. 2010 and placed into a dark cooler $\left(4{ }^{\circ} \mathrm{C}\right)$ to stratify for 1 month. In Jan. 2011 seeds were removed from the cooler and placed in a greenhouse at $21^{\circ} \mathrm{C}$. Germination was recorded after $60 \mathrm{~d}$.

To further evaluate fertility, additional reciprocal hybridizations between tetraploid $R$. hirta 'Cherry Brandy' and allotetraploids as well as between tetraploid $R$. 'Henry Eilers' H2008-239-004 and allotetraploids were made in the greenhouse in 2011. Seeds were treated in the same way as described previously.

Data were analyzed using analysis of variance (PROC GLM, SAS Version 9.1.3; SAS Institute Inc., Cary, NC) and means compared using Waller-Duncan K-ratio $t$ test $(P \leq 0.05)$.

\section{Results and Discussion}

Ploidy confirmation. The autotetraploids of $R$. subtomentosa had a mean genome size of $2 \mathrm{C}=41.80 \pm 0.70$ (SEM) pg, which is approximately twice that of the published genome size of diploid $R$. subtomentosa, $2 \mathrm{C}=21.9 \pm 0.17$ (SEM) pg (Palmer et al., 2009). The allotetraploid hybrids had a mean genome size of $2 \mathrm{C}=29.3 \pm 0.36$ (SEM) pg, which is consistent with the expected genome size of allotetraploids between $R$. subtomentosa and $R$. hirta.

Morphological traits, date of first anthesis, and perennialness. Morphological changes resulting from induced polyploidy varied by genotype and lines within genotype (Table 1). Plant height was reduced in some allopolyploid lines, increased in one (H2010-100001), and was not changed in others, including the autotetraploid lines, when compared with diploid controls. Number of stems either decreased or had no change in both auto- and allotetraploid lines. Inflorescence diameter increased, decreased, or remained unchanged for different allopolyploid lines and increased for the autotetraploid lines, whereas the number of inflorescences decreased for all induced polyploids compared with diploid controls. An increase in flower diameter is often associated with induced polyploids (Kehr, 1996; Zadoo et al., 1975) and can be associated with a decrease in the 
Table 1. Influence of induced polyploidy on morphology and date of anthesis among allotetraploid lines of $R$. subtomentosa $\times R$. hirta and autotetraploid lines of R. subtomentosa 'Henry Eilers'.

\begin{tabular}{|c|c|c|c|c|c|c|c|c|}
\hline Accession/line & Genotype & Cytotype & $\begin{array}{l}\text { Plant ht } \\
\quad(\mathrm{cm})\end{array}$ & $\begin{array}{l}\text { Internode length } \\
(\mathrm{mm})^{\mathrm{z}}\end{array}$ & $\begin{array}{l}\text { Number } \\
\text { of stems }\end{array}$ & $\begin{array}{l}\text { Inflorescence } \\
\text { diam }(\mathrm{mm})\end{array}$ & $\begin{array}{c}\text { Number of } \\
\text { inflorescences }\end{array}$ & $\begin{array}{c}\text { Date of } \\
\text { anthesis }^{\mathrm{x}}\end{array}$ \\
\hline \multicolumn{9}{|c|}{ R. subtomentos $a \times R$. hirta } \\
\hline Н2008-128-004 & 1 & $2 \mathrm{x}$ & $76.7 \mathrm{a}^{\mathrm{w}}$ & $33.0 \mathrm{a}$ & $11.4 \mathrm{a}$ & $77.9 \mathrm{a}$ & $112.5 \mathrm{a}$ & $6 / 22 c$ \\
\hline H2010-097-001 & 1 & $4 x$ & $68.7 \mathrm{bc}$ & $36.1 \mathrm{a}$ & $9.6 \mathrm{~b}$ & $69.6 \mathrm{~b}$ & $46.4 \mathrm{c}$ & $6 / 27 b$ \\
\hline H2010-098-001 & 1 & $4 x$ & $65.4 \mathrm{c}$ & $37.1 \mathrm{a}$ & $11.7 \mathrm{a}$ & $73.7 \mathrm{ab}$ & $68.2 \mathrm{~b}$ & $7 / 5 \mathrm{a}$ \\
\hline H2010-099-001 & 1 & $4 x$ & $72.0 \mathrm{ab}$ & $40.7 \mathrm{a}$ & $9.4 \mathrm{~b}$ & $71.9 \mathrm{ab}$ & $59.7 \mathrm{bc}$ & $7 / 6 \mathrm{a}$ \\
\hline H2008-128-006 & 2 & $2 \mathrm{x}$ & $76.0 \mathrm{a}$ & $36.5 \mathrm{a}$ & $12.0 \mathrm{a}$ & $83.7 \mathrm{a}$ & $71.8 \mathrm{a}$ & $6 / 13 b$ \\
\hline H2009-175-001 & 2 & $4 x$ & $69.7 \mathrm{~b}$ & $38.8 \mathrm{a}$ & $8.6 \mathrm{~b}$ & $73.2 \mathrm{~b}$ & $40.1 \mathrm{~b}$ & $7 / 8 \mathrm{a}$ \\
\hline H2009-175-002 & 2 & $4 x$ & $69.3 \mathrm{~b}$ & $42.5 \mathrm{a}$ & $6.9 \mathrm{~b}$ & $72.1 \mathrm{~b}$ & $43.5 \mathrm{~b}$ & $7 / 4 \mathrm{a}$ \\
\hline H2008-128-007 & 3 & $2 x$ & $62.2 \mathrm{~b}$ & $30.1 \mathrm{a}$ & $13.3 \mathrm{a}$ & $60.5 \mathrm{~b}$ & $114.4 \mathrm{a}$ & $6 / 23 b$ \\
\hline H2010-100-001 & 3 & $4 x$ & $71.4 \mathrm{a}$ & $35.9 \mathrm{a}$ & $7.8 \mathrm{~b}$ & $67.4 \mathrm{a}$ & $32.8 \mathrm{~b}$ & $7 / 4 \mathrm{a}$ \\
\hline H2010-101-001 & 3 & $4 x$ & $67.6 \mathrm{ab}$ & $31.8 \mathrm{a}$ & $6.8 \mathrm{~b}$ & $71.2 \mathrm{a}$ & $27.8 \mathrm{~b}$ & $7 / 4 \mathrm{a}$ \\
\hline \multicolumn{9}{|c|}{ R. subtomentosa 'Henry Eilers' } \\
\hline H2008-170-001 & 4 & $2 \mathrm{x}$ & $120.1 \mathrm{a}$ & $51.1 \mathrm{a}$ & $6.6 \mathrm{a}$ & $86.9 \mathrm{~b}$ & $60.4 \mathrm{a}$ & $7 / 27 \mathrm{a}$ \\
\hline H2008-239-002 & 4 & $4 x$ & $120.1 \mathrm{a}$ & $54.5 \mathrm{a}$ & $4.8 \mathrm{a}$ & $100.5 \mathrm{a}$ & $40.8 \mathrm{~b}$ & 7/31 a \\
\hline H2008-236-004 & 4 & $4 x$ & $115.0 \mathrm{a}$ & $49.0 \mathrm{a}$ & $5.5 \mathrm{a}$ & $95.8 \mathrm{a}$ & $42.6 \mathrm{~b}$ & $7 / 27 \mathrm{a}$ \\
\hline
\end{tabular}

${ }^{2}$ Internode length represents an average of the second and fifth internode from the base and second internode below the inflorescence.

${ }^{y}$ Number of stems arising from the crown.

${ }^{\mathrm{x}}$ Date anthers began dehiscing. Data collected in 2010.

${ }^{w}$ Mean separation, within columns and genotype, by Waller-Duncan, $P<0.05, \mathrm{n}=12$.

total number of flowers (Mackiewicz, 1965). The date of first anthesis was delayed for all allotetraploid lines but was unchanged for the autotetraploid lines. Delayed flowering is a common response to induced polyploidy (Kehr, 1996), so it is not unexpected the allotetraploid lines flowered later than their diploid cytotypes. There was no significant change in internode length for any of the polyploid lines in the experiment.

Phenotypically, there were no significant differences for any of the scored traits between the two autotetraploid lines, whereas variation among allopolyploid lines within a given genotype was observed. Because these lines should be isogenic (within genotype), this suggests variable changes in gene expression associated with induced allopolyploidy. Causes for genomic and gene expression changes in polyploids have been reviewed extensively and proposed mechanisms include both genetic (sequence deletions, rearrangements, subfunctionalization, gene repression and dominance, novel activation, dosage effects) and epigenetic factors (DNA methylation) (Adams and Wendel, 2005; Chen and Ni, 2006; Osborn et al., 2003). Studies on multiple polyploid lines suggest these changes in gene expression may be either repeatable or stochastic in nature. For example, in four Arabidopsis allotetraploid lines, several genes were consistently expressed overall four lines, whereas other genes were downregulated in some lines (Wang et al., 2004). Similarly, some genes have been shown to have consistent expression, whereas others have variable expression across artificially produced cotton allopolyploids (Adams and Wendel., 2005). Stochastic changes in gene expression may explain the variability observed in allopolyploid hybrids of $R$. subtomentosa $\times$ hirta.

It is also possible somaclonal variation may have been induced in Rudbeckia allopolyploids through in vitro culture. Somaclonal variation is often observed in in vitro-grown plants (Jain, 2001; Larkin and Scowcroft, 1981) and has been investigated in Echinacea purpurea (purple coneflower), a member of the Asteraceae and a close relative of Rudbeckia (Chuang et al., 2010). Chuang et al. (2010) found less than $1.5 \%$ (14 plants of 1087 sampled) of off types occurred in E. purpurea as a result of somaclonal variation from primary regenerants derived from shoot organogenesis using leaf explants. In rice, Müller et al. (1990) found plants regenerated from a single callus showed DNA polymorphisms as measured by random fragment length polymorphism analysis. Furthermore, long-term in vitro culture can also result in somaclonal variation, but varies by taxa, culture conditions, and duration (Turner et al., 2001). The diploid genotypes in our study were initiated through organogenesis from leaf tissues and all genotypes were maintained through several subculture cycles before and after polyploid induction, increasing the potential for somaclonal variation. Additionally, chimerism as a result of somaclonal variation could have occurred, which may account for variability within tetraploid lines originating from the same diploid microcutting.

In addition to the quantitative traits recorded, tubular or quilled ray florets, were observed in some autotetraploids from genotype 3 (Fig. 2). Neither parent of the $R$. subtomentosa $\times$ hirta cross for genotype 3 had a quilled petal phenotype. The appearance of the novel tubular ray florets has also occurred in induced tetraploids of Tanacetum parthenium (feverfew), another member of the Asteraceae (Majdi et al., 2010).

All plants from genotype 4 ( $R$. 'Henry Eilers' and its autotetraploids) showed perennial characteristics and survived at the end of the season and through the winter (Fig. 3). There was variable end-of-season survival for hybrid genotypes and generally much lower overwinter survival (less than 25\%), with the exception of genotype 1 , in which the diploid hybrid, H2008-128-004, had 83\%

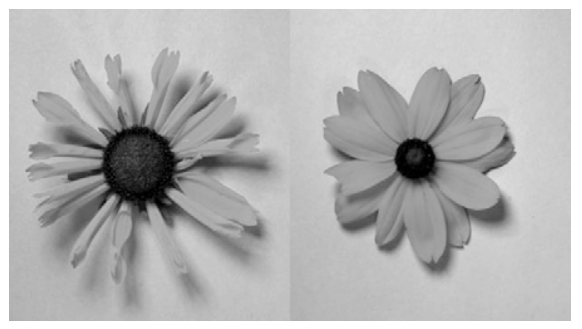

Fig. 2. Novel quilled petal morphology in tetraploid clone compared with isogenic diploid clone. Bar $=30 \mathrm{~mm}$.

overwinter survival. End-of-season data were included in the analysis to reflect the inability for some accessions to form a crown and spontaneously senesce at the end of the growing season, a trait associated with botanical annuals. Genotype 3 had a particularly low end-of-season survival rate with only $17 \%$ to $25 \%$ of plants surviving at that time. Induced polyploidy significantly decreased overwinter survival in genotype 1 and significantly decreased fall survival in genotype 2 . There was no other ploidy effect seen in any of the other genotypes.

Fertility. Pollen staining typically increased for allotetraploid lines compared with diploid cytotypes and decreased for autotetraploids of $R$. 'Henry Eilers' (Table 2). Furthermore, controlled crosses between the tetraploid R. hirta 'Cherry Brandy' and allotetraploids resulted in 15 hybrids (Table 2), demonstrating limited male fertility. Hybrids had genome sizes of $\approx 21 \mathrm{pg}$, intermediate of 'Cherry Brandy' ( $\approx 14$ pg) and allotetraploids ( $\approx 29$ pg).

No germination was observed for any of the seeds collected in 2010 from allotetraploid lines. The allotetraploids had pollen available from many sources, including other genotypes of allotetraploids, tetraploid $R$. hirta 'Cherry Brandy', diploid R. hirta 'Toto Gold', 
and diploid and tetraploid R. subtomentosa. From controlled crosses conducted in 2011, H2010-098-001 × H2008-239-004 produced one seedling, H2010-097-001 × H2008-239004 produced one seedling, and H2010-097001 self-pollinated produced one seedling. All three seedlings had genome sizes similar to the maternal parent $(\approx 29 \mathrm{pg})$ indicating that seedlings arose from self-fertilization or apomixis. From the 12 diploid $R$. 'Henry Eilers' plants sampled (36 flower heads total) in 2010, 69 seeds germinated and all seedlings had a genome size consistent with diploid $R$. subtomentosa. Rudbeckia subtomentosa and $R$. hirta are highly selfincompatible but can sometimes produce apomictic seeds through pseudogamy (Palmer et al., 2009). Autotetraploid accession H2008-239-002 had nine seeds germinate and accession H2008-239-004 had four seeds germinate (a significant reduction compared with diploids, $P<0.05$ ). All 13 seedlings from the autotetraploids had genome sizes of $31.39 \pm 0.32 \mathrm{pg}$, consistent with triploid $R$. subtomentosa. Based on the genome size of the offspring, it is likely diploid wild-type R. subtomentosa was the pollen parent. The two autotetraploids were induced from the same diploid genotype and the self-incompatibility mechanism in R. subtomentosa may have prevented these lines from intercrossing. No tetraploid of another genotype of $R$. subtomentosa was available at the time of the experiment, which, along with self-incompatibility between

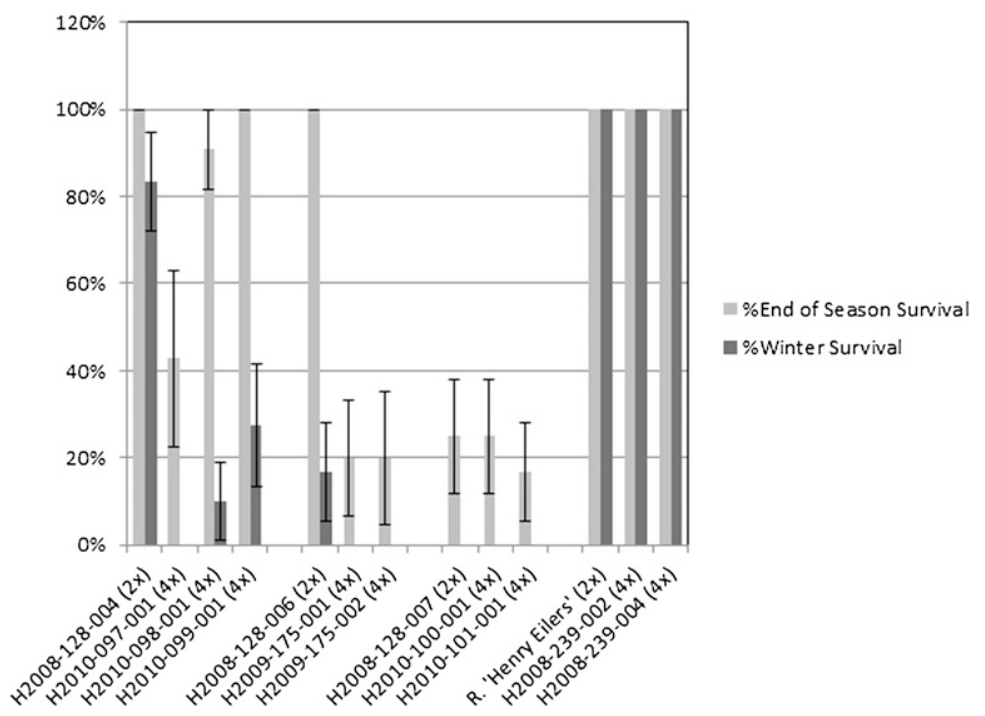

Fig. 3. Percentage survival ( \pm SEM) of diploid and allotetraploid lines of $R$. subtomentosa $\times R$. hirta and diploid and autotetraploid lines of $R$. subtomentosa 'Henry Eilers' at the end of the growing season (Sept. 2010) and the next spring (May 2011). the autotetraploid lines, could explain why no tetraploid seedlings were found. Female fertility, although low, was retained in the autopolyploids.

Seedlings obtained from controlled crosses of $R$. hirta 'Cherry Brandy' with various allotetraploids indicated there was limited restoration of male fertility in allotetraploids. A small number seedlings was obtained from wallotetraploids of $R$. subtomentosa $\times$ hirta indicating limited female fertility from either selfing or apomixis. Chromosome doubling to restore fertility to sterile-wide hybrids has been used with varying success. Contreras et al. (2007) reported an increase in pollen staining from $0 \%$ to $68 \%$ and an increase in seed germination from $0 \%$ to $12 \%$ in an induced allotetraploid of Rhododendron L. 'Fragrant Affinity'. Olsen et al. (2006) also reported the restoration of both male and female fertility in allotetraploids of $\times$ Chitalpa Ellias \& Wisura. In contrast for allotetraploids of Alstroemeria aurea $\times$ A. caryophyllae, fertility was not restored, although pollen staining increased from $0 \%$ in the diploid hybrids to $12 \%$ in the allotetraploids ( $\mathrm{Lu}$ and Bridgen, 1997).

The effects of induced polyploidy on the fertility and morphology of allotetraploids and autotetraploids of Rudbeckia spp. were variable both among and within genotypes. Induced autotetraploids of $R$. subtomentosa 'Henry Eilers' displayed larger flowers, although the plants maintained a large stature and had a reduced number of inflorescences. Some desirable phenotypes were recovered in the allotetraploids, and limited restoration of fertility may allow future breeding and plant improvement. The higher survivability at both the end of season and through winter of one hybrid accession suggests that larger $\mathrm{F}_{1}$ populations between $R$. subtomentosa $\times$ $R$. hirta could also yield more desirable perennial types.

Table 2. Pollen viability among diploid and allotetraploid lines of $R$. subtomentosa $\times$ R. hirta and diploid and autotetraploid lines of R. subtomentosa 'Henry Eilers'.

\begin{tabular}{|c|c|c|c|c|c|}
\hline Accession/line & Genotype & Ploidy & $\begin{array}{c}2010 \\
\text { Pollen staining }(\%)^{\mathrm{z}}\end{array}$ & $\begin{array}{c}2011 \\
\text { Pollen staining }(\%)^{\mathrm{z}}\end{array}$ & $\begin{array}{c}2011 \\
\text { (hybrid seedlings) }\end{array}$ \\
\hline H2008-128-004 & 1 & $2 \mathrm{x}$ & $7.9 \mathrm{c}$ & $6.9 \mathrm{c}$ & \\
\hline H2010-098-001 & 1 & $4 \mathrm{x}$ & $62.5 \mathrm{a}$ & $42.5 \mathrm{ab}$ & 6 \\
\hline H2010-099-001 & 1 & $4 \mathrm{x}$ & $39.3 \mathrm{~b}$ & - & 0 \\
\hline H2011-154-001 & 1 & $4 \mathrm{x}$ & - & $42.8 \mathrm{a}$ & 4 \\
\hline H2008-128-006 & 2 & $2 \mathrm{x}$ & $12.1 \mathrm{~b}$ & $8.0 \mathrm{c}$ & \\
\hline H2009-175-006 & 2 & $4 \mathrm{x}$ & - & $56.0 \mathrm{a}$ & - \\
\hline H2008-128-007 & $3^{y}$ & $2 \mathrm{x}$ & 5.1 & - & - \\
\hline H2010-100-001 & 3 & $4 \mathrm{x}$ & 30.7 & - & - \\
\hline H2010-101-001 & 3 & $4 \mathrm{x}$ & 15.3 & 27.2 & - \\
\hline \multicolumn{6}{|c|}{ R. subtomentosa 'Henry Eilers' } \\
\hline H2008-170-001 & 4 & $2 \mathrm{x}$ & $95.7 \mathrm{a}$ & - & - \\
\hline
\end{tabular}

${ }^{2}$ Mean separation, within columns for each genotype, using Waller-Duncan K-ratio $t$ test, $P \leq 0.05, \mathrm{n}=12$.

${ }^{y}$ No statistics available for genotype three due to low sample sizes in $2010(\mathrm{n}=1)$ and unavailability of accessions in 2011.

${ }^{\mathrm{x}}$ Hybrid seedlings from $R$. hirta 'Cherry Brandy' $\times($ R. subtomentos $a \times R$. hirta $)$ allotetraploids. Seedlings with genome sizes of $\approx 21 \mathrm{pg}$ were determined to be hybrids. 


\section{Literature Cited}

Adams, K.L. and J.F. Wendel. 2005. Novel patterns of gene expression in polyploid plants. Trends Genet. 21:539-543.

Armitage, A.M. 1997. Herbaceous perennial plants: A treatise on their identification, culture, and garden attributes. 2nd Ed. Stipes Publishing, Champaign, IL.

Chahal, G.S. and S.S. Gosal. 2002. Principles and procedures of plant breeding: Biotechnological and conventional approaches. Alpha Sci. Intl., Ltd., Pangbourne, UK.

Chen, Z.J. and Z. Ni. 2006. Mechanisms of genomic rearrangements and gene expression changes in plant polyploids. Bioessays 28:240 252.

Chuang, S.J., C.L. Chen, J.J. Chen, and J.M. Sung. 2010. Using morphological diagnosis and molecular markers to assess the clonal fidelity of micropropagated Echinacea purpurea regenerants. Biol. Plant. 54:539-542.

Contreras, R.N., T.G. Ranney, and S.P. Tallury. 2007. Reproductive behavior of diploid and allotetraploid Rhododendron L. 'Fragrant Affinity'. HortScience 42:31-34.

Driver, J.A. and A.H. Kuniyuki. 1984. In vitro propagation of paradox walnut rootstock. HortScience 19:507-509.

Fulcher, A., W.C. Dunwell, and D. Wolfe. 2003. Rudbeckia taxa evaluation. Southern Nurserymen's Assoc. Res. Conf. 48:510-512.

Greihuber, J., E.M. Temsch, and J.C.M. Loureiro. 2007. Nuclear DNA content measurement, p. 67-101. In: Doležel. J., J. Greilhuber, and J. Suda (eds.). Flow cytometry with plant cells: Analysis of genes, chromosomes, and genomes. Wiley-VCH, Weinheim, Germany.

Hansen, R. and F. Stahl. 1993. Perennials and their garden habitats. Timber Press, Portland, OR.
Harkess, R.L. and R.E. Lyons. 1994. Rudbeckia hirta L.: A versatile North American wildflower. HortScience 29:134-227.

Horn, W. 2002. Breeding methods and breeding research, p. 47-83. In: Breeding for ornamentals: Classical and molecular approaches. Kluwer Academic Publishers, Dordrecht, The Netherlands.

Jain, S.M. 2001. Tissue culture-derived variation in crop improvement. Euphytica 118:153-166.

Kehr, A.E. 1996. Polyploids in rhododendron breeding. J. Amer. Rhododendron Soc. 50:215-217.

Larkin, P.J. and W.R. Scowcroft. 1981. Somaclonal variation-A novel source of variability from cell cultures for plant improvement. Theor. Appl. Genet. 60:197-214.

Lu, C. and M.P. Bridgen. 1997. Chromosome doubling and fertility study of Alstroemeria aurea $\times$ A. caryophyllaea. Euphytica 94:75-81.

Mackiewicz, H.O. 1965. Studies on di- and tetraploid aslike clover (Trifolium hybridum L.) part II, flower morphology and the problem of fertility. Genetica Polonica 6:41-77.

Majdi, M., G. Karimzadeh, M.A. Malboobi, R. Omidbaigi, and G. Mirzaghaderi. 2010. Induction of tetraploidy to feverfew (Tanacetum parthenium Schulz-Bip.): Morphological, physiological, cytological, and phytochemical changes. HortScience 45:16-21.

Martin, A. and N. Jouve. 1992. Cytogenetics of $F_{1}$ and their progenies, p. 82-105. In: Kalloo, G. and J.B. Chowdhury (eds.). Distant hybridization of crop plants. Springer-Verlag, Berlin, Germany.

Müller, E., P.T.H. Brown, S. Hartke, and H. Lörz. 1990. DNA variation in tissue-culture-derived rice plants. Theor. Appl. Genet. 80:673-679.

Olsen, R.T., T.G. Ranney, and Z. Viloria. 2006. Reproductive behavior of induced allotetraploid $\times$ Chitalpa and in vitro embryo culture of polyploidy progeny. J. Amer. Soc. Hort. Sci. 131:716-724

Osborn, T.C., J.C. Pires, J.A. Birchler, D.L. Auger, Z.J. Chen, H. Lee, L. Comai, A. Madlung, R.W. Doerge, V. Colot, and R.A. Martienssen. 2003. Understanding mechanisms of novel gene expression in polyploids. Trends Genet. 19:141-147.

Palmer, I.E., R.E. Bir, N.P. Lynch, and T.G. Ranney. 2009. Crossability, cytogenetics, and reproductive pathways in Rudbeckia subgenus Rudbeckia. HortScience 44:44-48.

Palmer, I.E., D.H. Touchell, and T.G. Ranney. 2008. In-vitro polyploid induction of Rudbeckia spp. Southern Nurserymen's Assn. Res. Conf. 53:186-189.

Perdue, R.E., Jr. 1957. Synapsis of Rudbeckia subg. Rudbeckia. Rhodora 59:293-299.

Ranney, T.G. 2006. Polyploid: From evolution to new plant development. Combined Proc. Intl. Plant Propagators Soc. 56:137-142.

Turner, S., S.L. Krauss, E. Bunn, T. Senaratna, K. Dixon, B. Tan, and D. Touchell. 2001. Genetic fidelity and viability of Anigozanthos viridis following tissue culture, cold storage, and cryopreservation. Plant Sci. 161:1099-1106.

Urbatsch, L.E., B.G. Baldwin, and M.J. Donoghue. 2000. Phylogeny of the coneflowers and relatives (heliantheae: Asteraceae) based on nuclear rDNA internal transcribed spacer (ITS) sequences and chloroplast DNA restriction site data. Syst. Bot. 25:539-565.

Wang, J., L. Tian, A. Madlung, H. Lee, M. Chen, J.J. Lee, B. Watson, T. Kagochi, L. Comai, and Z.J. Chen. 2004. Stochastic and epigenetic changes of gene expression in Arabidopsis polyploids. Genet. 167:1961-1973.

Zadoo, S.N., P.P. Roy, and T.N. Khoshoo. 1975. Cytogenetics of cultivated Bouganvilleas. V. Induced tetraploidy and restoration of fertility in sterile cultivars. Euphytica 24:517-524. 